\title{
ANÁLISE DO DISCURSO NO INSTITUCIONALISMO ORGANIZACIONAL: possibilidades a partir do discurso midiático
}

\section{1- Samir Adamoglu de Oliveira*}

Doutor em Administração pela Universidade Federal do Paraná (PPGADM/UFPR), Brasil.

Professor do Programa de Mestrado e Doutorado em Administração da Universidade Positivo (PMDA-UP), Brasil.

Pesquisador Associado do Instituto Brasileiro de Estudos e Pesquisas Sociais (IBEPES).

samiroliveira09@hotmail.com

http://lattes.cnpq.br/3766511422208153

\section{2- Renata Fragoso Maria Sobrinho}

Doutoranda em Administração pelo Programa de Mestrado e Doutorado em Administração da Universidade Positivo (PMDA-UP), Brasil.

Coordenadora dos Cursos Superiores de Tecnologia das Faculdades FACEL e Spei, Brasil.

renatafsobrinho@gmail.com

http://lattes.cnpq.br/7344840931992674

\section{3- Edson Ronaldo Guarido Filho}

Doutor em Administração pelo Programa de Pós-Graduação em Administração da Universidade Federal do Paraná (PPGADM/UFPR), Brasil.

Professor do Programa de Mestrado e Doutorado em Administração da Universidade Positivo (PMDA-UP), Brasil.

Professor do Programa de Pós-Graduação em Gestão, Ciência e Tecnologia da Informação da Universidade Federal do Paraná (PPGCI-UFPR), Brasil.

edson.guarido@gmail.com

http://lattes.cnpq.br/2435628775717990

\section{Editor responsável pela submissão:}

Diego Maganhotto Coraiola.

Artigo analisado via processo de revisão duplo cego (Double-blind).

Recebido em: 01/03/2015

Aprovado em: 13/05/2016

Última Alteração: 27/06/2016

\footnotetext{
* Contato Principal: Universidade Positivo - Rua Professor Pedro Viriato Parigot de Souza, 5300, CEP: 81.280-330, Cidade
} Industrial. Curitiba. Paraná. Brasil 


\title{
ANÁLISE DO DISCURSO NO INSTITUCIONALISMO ORGANIZACIONAL: POSSIBILIDADES A PARTIR DO DISCURSO MIDIÁTICO
}

\section{RESUMO}

O objetivo do ensaio é discutir, dentro dos estudos organizacionais (EORs), as implicações e possibilidades metodológicas de se analisar a participação do discurso midiático na (re)construção social de padrões institucionais vigentes. Inspirado no framework de Phillips, Lawrence e Hardy (2004), a argumentação baseia-se na articulação do discurso com o institucionalismo organizacional, inserindo a mídia como participante da construção da realidade social enquanto ator que influencia e é influenciado por seu contexto institucional, como um sistema simbólico e como loci de interação. Implicações e possibilidades acerca de como proceder metodologicamente de modo a empreender investigações no empírico que deem conta de abordar e estudar o discurso midiático nas organizações - e em campos organizacionais -, são aventadas.

\section{Palavras-Chave}

Instituições; Discurso midiático; Práticas discursivas.

\section{DISCOURSE ANALYSIS IN ORGANIZATIONAL INSTITUTIONALISM: POSSIBILITIES FROM MEDIA DISCOURSE}

\begin{abstract}
The essay aims to discuss implications and methodological possibilities of analyzing media discourse participating in the social (re)construction of active institutional patterns. Drawing on Phillips, Lawrence and Hardy's (2004) framework, discourse and organizational institutionalism are articulated, inserting media as a participant in constructing social reality as an actor that is both influenced by and influential inside in an institutional context, appearing as a symbolic system, and as an interactional loci. Implications and possibilities regarding how to proceed methodologically in terms of performing empirical investigations approaching and studying media discourse in organizations - and in organizational fields - are outlined.
\end{abstract}

\section{Keywords}

Institutions; Media discourse; Discursive practices. 


\section{Introdução}

Organizações privadas, públicas e não governamentais possuem suas estratégias e práticas condicionadas por estruturas sociais mais amplas, cuja influência recai nas diversas dimensões organizacionais em diferentes níveis e instâncias de análise, a partir de relações interorganizacionais e de campo (Scott, 2008a). Ao mesmo tempo, entende-se que estas mesmas organizações possuem capacidade de agência, ou seja, podem agir de forma favorável ou contrária a tais influências, incorrendo numa relação recursiva, devido à imersão das suas ações nessas mesmas esferas societais (Machado-da-Silva, Fonseca \& Crubellate, 2005).

Subjacente à relação recursiva, chama-se a atenção ao elemento discursivo. Teoricamente, o elemento discursivo pode ser trabalhado e investigado com propriedade pelo institucionalismo organizacional (Lok \& Willmott, 2006; Phillips, Lawrence \& Hardy, 2004). Para tanto, precisa-se de uma maior sensibilidade com questões anteriores ao próprio estudo sobre o discurso organizacional: é necessário compreender adequadamente o discurso como prática social por meio do reconhecimento da importância da linguagem em uso para a compreensão do processo de institucionalização (Fairclough, 2001). Já metodologicamente, tendo como base a proposta discursiva-institucional de Phillips, Lawrence e Hardy (2004), são necessários desenvolvimentos e aprimoramentos, inclusive de ordem epistemológica, para conseguir melhor captar os processos de produção e reprodução de padrões institucionais vigentes em campos organizacionais e em setores da sociedade civil.

Partindo do pressuposto de que as organizações podem ser consideradas atores sociais relevantes, as quais constituem a realidade social por meio do uso da linguagem em práticas discursivas, pretende-se avançar para uma análise do discurso no institucionalismo organizacional por meio de uma discussão sobre as possibilidades metodológicas a partir da seguinte indagação: de que forma os discursos participam da construção e reconstrução social de padrões institucionais vigentes, influenciando a legitimidade de práticas e modelos de gestão em determinados campos organizacionais? Assim, acredita-se que é necessário despender maior esforço e atenção às questões fenomenológicas e à pragmática da linguagem, de forma precisa e complementar (Phillips \& Malhotra, 2008), para o efetivo desenvolvimento de um aparato analítico que potencialize as investigações dos processos de (des)institucionalização e de seus efeitos na construção social da realidade em sua recursividade.

Para atender a este propósito, o ensaio estrutura-se em quatro seções, considerando esta introdução. A seção seguinte é desenvolvida enfocando o framework (modelo) analítico que dá sustentação epistemológica anuente à problemática a ser discutida, expondo pontos em que se pretende revisá-lo e expandi-lo, em termos de potencial explicativo da dinâmica das organizações; nela, elege-se a mídia e os discursos (re)produzidos por esse ator organizacional enquanto exemplo empírico e objeto de estudo, a partir de algumas proposições de pesquisa. Na terceira seção refletese, de forma não exaustiva, sobre potenciais percursos metodológicos que viabilizem adequadamente a operacionalização de uma análise do discurso voltado ao institucionalismo organizacional no objeto midiático. Por fim, a quarta seção indica as contribuições científicas desse ensaio, ensejando aproximações teórico-empíricas possíveis, a fim de engajar esforços futuros no desenvolvimento e utilização investigativa de uma análise do discurso válida para o institucionalismo organizacional.

\section{Linguagem, Discurso e Instituições}

O estudo da linguagem e do discurso para o entendimento da realidade (Berger \& Luckmann, 2003) foi elucidado pelo que se convenciona chamar de 'giro linguístico' (Oliveira, 2006) ocorrido no final da década de 1960, fortemente influenciada pelos trabalhos filosóficos de Ludwig Wittgenstein e Martin Heidegger (Stern, 2003). Entretanto, somente a partir dos anos 1990 a linguagem passou a ser enfocada nos Estudos Organizacionais (EORs), incluindo estudos orientados por abordagens institucionalistas. Primeiramente, autores como DiMaggio (1988) e Oliver (1991; 1992) se esforçaram em demonstrar a possibilidade de agência organizacional e, mais recentemente, outros autores, como Phillips, Lawrence e Hardy (2004; 2006), Phillips e Malhotra (2008) e Schmidt (2008), concentraram seus esforços na tentativa de explicar as relações entre discurso e instituições, levando em conta o amplo alcance analítico desses temas, sedimentando-os, sobretudo, no atentar para a centralidade da linguagem na vida humana. Deste modo, a construção da realidade, neste ensaio, é entendida por meio da linguagem, ou seja, a construção social, ao ser sustentada pelo vasto sistema de sinais e estruturas, proporciona à linguagem o caráter de alicerce nuclear de ação na dimensão social, constituindo coletivos e coletividades numa indissociável relação entre sujeito e realidade (Oliveira, 2006; Rorty, 1994). Com efeito, a linguagem constitui "[ ...] o mais importante conteúdo e o mais importante instrumento da socialização" (Berger \& Luckmann, 2003, p. 179). 
Apesar da expressiva e crescente atenção ao papel da linguagem em distintas áreas do campo interdisciplinar da Administração (Greenwood, Oliver, Sahlin \& Suddaby, 2008), ainda se apresentam muitas divergências quanto as suas formas de investigação e entendimento (Alvesson $\&$ Kärreman, 2000b; Grant, Hardy, Oswick \& Putnam, 2004; Grant, Keenoy \& Oswick, 1998; Fairclough, 2001; Phillips \& Oswick, 2012), o que reforça sua pluralidade e sua relevância (Alvesson \& Kärreman, 2000a; Astley \& Zammuto, 1992; Czarniawska, 2013) dada pela sistematicidade e potencial explicativo para as organizações (Taylor \& Robichaud, 2004).

Condizente com o exposto e com a epistemologia construtivista do discurso, o institucionalismo organizacional pode ser uma via de desenvolvimentos conceituais centrados na linguagem justamente pela importância desta na criação e reprodução das instituições, sendo microfundamento operante na sua constituição, mediante seu uso cotidiano (Alvesson $\&$ Kärreman, 2000b; Berger \& Luckmann, 2003; Cornelissen et al., 2015; Phillips \& Malhotra, 2008). Entendendo as organizações como atores sociais que apresentam capacidade de agência e cujas ações refletem a forma como interpretam a realidade do campo e dos setores onde atuam, o institucionalismo organizacional preocupa-se em estudar de que forma comportamentos sociais são alicerçados em entendimentos cognitivos e em sistemas normativos que atribuem significado às interações no plano da vida humana, viabilizando certa auto-reprodução de uma ordem social (Greenwood et al., 2008; Phillips \& Malhotra, 2008).

Desta forma, o modelo analítico apresentado por Phillips, Lawrence e Hardy (2004; 2006) reflete acerca de como as ações podem participar do processo de (des)institucionalização por meio da criação de textos e discursos. É importante salientar que o texto é uma expressão linguística, verbal ou não verbal, capaz de armazenar propriedades institucionais, por meio do qual o processo de construção da legitimidade é viabilizado pela perpetuação da dinâmica institucional mediante práticas que compõem os discursos em suas ordens contextuais. Neste sentido, a perpetuação das instituições, com suas práticas, ocorre por meio da linguagem, ou seja, a linguagem, por meio de seu exercício prático, é socialmente moldada ao mesmo tempo em que molda esse mesmo 'social', evidenciando, desta forma, sua dimensão pragmática - de uso, de ação prática (Alvesson \& Kärreman, 2000a; Astley \& Zammuto, 1992; Czarniawska, 2013).

Diante do exposto, pode-se dizer que estas ações produtoras de textos são dotadas de duas características: (i) a legitimidade; e (ii) a acepção de novidade (Phillips, Lawrence \& Hardy, 2004). A legitimidade é entendida como "[...] uma percepção ou pressuposição generalizada de que as ações de uma entidade são desejáveis, boas, ou apropriadas dentro de algum sistema socialmente construído de normas, valores, crenças, e definições" (Suchman, 1995, p. 574, tradução nossa). É preciso que a ação seja socialmente aceita e reconhecida enquanto apropriada, adequada ou correta. Por conta disso, a ação é indissociável dos padrões institucionalizados, devendo ser concomitantemente conservadora e inovadora, aludindo, com isso, à noção dialética entre persistência e mudança da realidade (Farjoun, 2010). Já a segunda característica, a novidade ou surpresa da ação, refere-se à produção de um sentido organizacional condizente ao conjunto de significados intersubjetivamente compartilhados em nível organizacional, de forma a orientar as ações de outros atores e a desencadear processos comunicativos organizacionais (sensemaking organizacional) (Taylor \& Robichaud, 2004). Assim, alcança-se uma compreensão multifuncional e multissemiótica dos textos, devido à variedade de possibilidades de produção de sentido e significado num evento comunicativo.

O sentido produzido pode originar discursos, cujo processo, segundo Phillips, Lawrence e Hardy (2004), ocorre por meio de um ator condutor do texto sob três circunstâncias: (i) ator possuidor de um papel central na rede - quanto mais central a posição ocupada na rede, maior a capacidade de articulação e mobilização de outros atores; (ii) ator detentor de meios para coagir a propagação do discurso, exercendo poder; e (iii) ator 'possuidor de voz' (warranting voice) ou legitimidade discursiva, que se refere à habilidade reconhecida de falar legitimamente de determinados assuntos em nome de outros atores (Phillips, Lawrence \& Hardy, 2004). É importante ressaltar que, apesar de analisados separadamente, essas três circunstâncias não são excludentes entre si.

Diante do exposto, o discurso é entendido, neste ensaio, como um conjunto inter-relacionado de textos que proporcionam significado a um objeto por meio da produção, disseminação e consumo destes textos, tendo como referência as estruturas e práticas que os subjazem (Hardy, Palmer \& Phillips, 2000; Phillips, Lawrence \& Hardy, 2004; 2006). Este entendimento remete a uma forma de uso da linguagem em particular que considera tanto o aspecto interacional cotidiano quanto o aspecto da construção social da realidade, pelo fato de o discurso também contemplar, por um lado, uma forma de saber e, por outro, um conjunto de relações de poder e de dominação, privilegiando um discurso a outros, silenciando-os, omitindo-os etc. (Fairclough, 1995). De forma complementar, todo discurso praticado num contexto social é, para Fairclough (1995, p. 55, tradução nossa), envolvido em uma rede de relações que constituem as "ordens do discurso", similares a domínios de 
hegemonia cultural ou de lógicas institucionais (Friedland \& Alford, 1991). Estas ordens combinam e articulam diferentes discursos, diferentes gêneros e diferentes estilos (Fairclough, 2005) válidos e operantes dentro de um determinado contexto, manifestos em diferentes tipos de texto e organizados em um arranjo que poderia ser visualizado como um 'mosaico' de práticas discursivas (Fairclough, 1995), atribuindo complexidade ao tecido institucional. Por combinar diferentes discursos, gêneros e estilos, estas ordens evidenciam pontos de tensão e conflito a partir das suas fronteiras mais ou menos esboçadas, principalmente se a sociedade for percebida como sendo um sistema interinstitucional potencialmente contraditório em seu caráter (Friedland \& Alford, 1991).

Phillips, Lawrence e Hardy (2004), pautados por este entendimento, consideram as relações de poder, em seu modelo de análise de discurso, por meio dos processos de intertextualidade, sejam estes entre textos ou entre discursos, por acreditarem que é a partir desses processos que se criam tensões e laços relacionais no exercício de poder (Zoller, 2014). Ao passo que a intertextualidade é justamente o que dinamiza as ordens discursivas acima indicadas, vislumbra-se a prática discursiva enquanto elo entre o plano macro ou institucional - que abarca os elementos mais duradouros da realidade cotidiana - e o plano micro - que abarca elementos de natureza mais situacional, mas, tampouco desconectados da macro-esfera. O discurso, portanto, para Phillips, Lawrence e Hardy (2004), também explica o status vigente e os aspectos duradouros do plano institucional o qual condiciona, em diferentes graus de influência, os eventos situacionais e os aspectos voláteis do plano da práxis, na qual ocorrem os silenciamentos, as marginalizações e as supressões de outros textos, numa dinâmica recursiva em que se implicam dominação e resistência (Farjoun, 2010; Lawrence, 2008). Neste aspecto, o modelo de Phillips, Lawrence e Hardy (2004), cuja inspiração remete-se à análise crítica de discurso de Fairclough (2001), preserva possibilidade 'crítica' ao viabilizar a investigação e avaliação da tensão existente entre a influência dos discursos vigentes na esfera macro na produção dos textos na esfera micro, possibilitando enxergar as articulações políticas empreendidas - devido à mobilização de capitais distintos entre atores organizacionais dentro de campos de ação estratégica - e os efeitos dessas ações - endossos, restrições, autorizações, mascaramentos, alterações etc. -, de forma a habilitar e restringir o que 'se diz' e o que 'não se diz' entre os textos (Lounsbury, 2003; Westwood \& Clegg, 2003) ${ }^{1}$. Complementando esse raciocínio, Wooten e Hoffman (2008) salientam que essas articulações políticas são, por vezes, o próprio elemento que define um "campo organizacional", o qual pode ser entendido como o espaço de disputas discursivas e de embates dialógicos, nos quais consensos e dissensos são produzidos e reproduzidos, configurando, dessa forma, tal espaço.

Com base no exposto, é possível estabelecer uma relação mutuamente constitutiva entre discurso, texto e ação, na qual "[ ...] os significados dos discursos são socialmente compartilhados, emanando das ações dos atores ao produzirem textos; concomitantemente, os discursos dão significados a essas ações, constituindo, portanto, o mundo social" (Phillips, Lawrence \& Hardy, 2004, p. 636, tradução nossa). Influenciadas por ações e discursos anteriores, as instituições, ao mesmo tempo em que são entendidas como produtos da atividade discursiva (Phillips, Lawrence \& Hardy, 2004), condicionam as atividades em nível de grupo e individual, as quais condicionarão a produção, manutenção ou ruptura dos discursos, num processo recursivo. Fairclough (1995, p. 56, tradução nossa), em complemento a essa noção, afirma que a "[ ...] análise de qualquer discurso em particular [ ...] envolve a alternância entre focos geminais e complementares essenciais, a saber: (i) eventos comunicativos; e, (ii) a ordem do discurso". Essa relação, ainda segundo o autor, também é evidenciada quando uma "análise crítica do discurso acerca de um evento comunicativo é a análise das relações entre três dimensões ou facetas desse evento", sendo elas: "texto, prática discursiva, e prática sociocultural" (Fairclough, 1995, p. 57, grifo do autor; tradução nossa).

O nível micro de análise pode ser associado ao texto, remetendo à ação situada do que efetivamente se realiza e se faz, no cotidiano da ação humana; o nível meso de análise pode ser associado à prática discursiva, remetendo à produção, disseminação e consumo de textos; e, por fim, o nível macro de análise pode ser associado à prática sociocultural, remetendo à noção de discurso como prática social. Investigar a dinâmica 'texto' $\leftrightarrow$ 'prática discursiva' $\leftrightarrow$ 'discurso' seguindo essa lógica multinível significa investigar questões de 'intertextualidade' e 'interdiscursividade', levando-se em conta alguma(s) das circunstâncias de produção e disseminação de textos influentes em discursos vigentes que, por fim, impliquem processos de (des)institucionalização.

Neste ensaio teórico, entende-se que é a prática discursiva que faz a mediação da relação entre os níveis micro e macro, numa análise social. Tomando um tipo de discurso que se promulga como sendo presente no cotidiano das organizações e dos próprios indivíduos - o discurso da mídia -, tentar-se-á em seguida exemplificar como esse aparato analítico pode ser aplicado, circunscrevendo-o especificamente à dinâmica discursivo-organizacional da mídia. Assim, mais do que indicar que o discurso da mídia pode influenciar organizações, intenta-se aqui ancorar como a mídia também pode ser entendida como um ator organizacional relevante, cuja influência dos seus 
discursos (re)produzidos cristaliza-se enquanto uma problemática institucional relevante para a vida organizacional e, conseguintemente, em sociedade - numa lógica recursiva.

\subsection{A Mídia e seus Discursos: Um Objeto para Estudo Empírico}

Um ator organizacional pode ser entendido como uma organização reflexivamente conhecedora das suas práticas e das práticas do campo organizacional onde se situa, além de ser capaz de entendimento e de monitoramento das situações do cotidiano, dos resultados das suas ações e das ações de outras organizações com as quais ele mantenha algum grau de relação, em uma dada esfera institucional (Scott, 2008a). Ainda, o ator organizacional pode ser entendido como um 'carrier', ou seja, um condutor de práticas, ideias, sentidos, significados e de outros elementos sociais e culturais (Scott, 2008b). Ao partir do pressuposto de que a linguagem é fundamentalmente ação, a investigação dos processos comunicativos e discursivos do cotidiano dos sujeitos nas/das organizações pode se tornar uma via promissora de compreensão das questões centrais do institucionalismo organizacional (Cornelissen et al., 2015). Ainda mais se considerar que as formas de ação e de interação utilizadas pelos indivíduos para construir a realidade social são inextricavelmente associadas aos meios empregados na comunicação - em sua ampla significância de impacto social e histórica que foi ao longo do tempo e espaço, constituindo o tecido da vida social (Thompson, 1995). Diante desta conceituação, a mídia pode ser vista tanto como um ator que influencia e é influenciado por seu contexto institucional quanto como um sistema simbólico que atua como um 'carrier'. Desse modo, mesmo sendo tradicionalmente entendida como um conjunto de condutores ou meios de comunicação orientada a amplas parcelas da sociedade civil, ela também representa um dos agentes que constituem o tecido social e cultural (Rice \& Leonardi, 2014; Thompson, 1995)

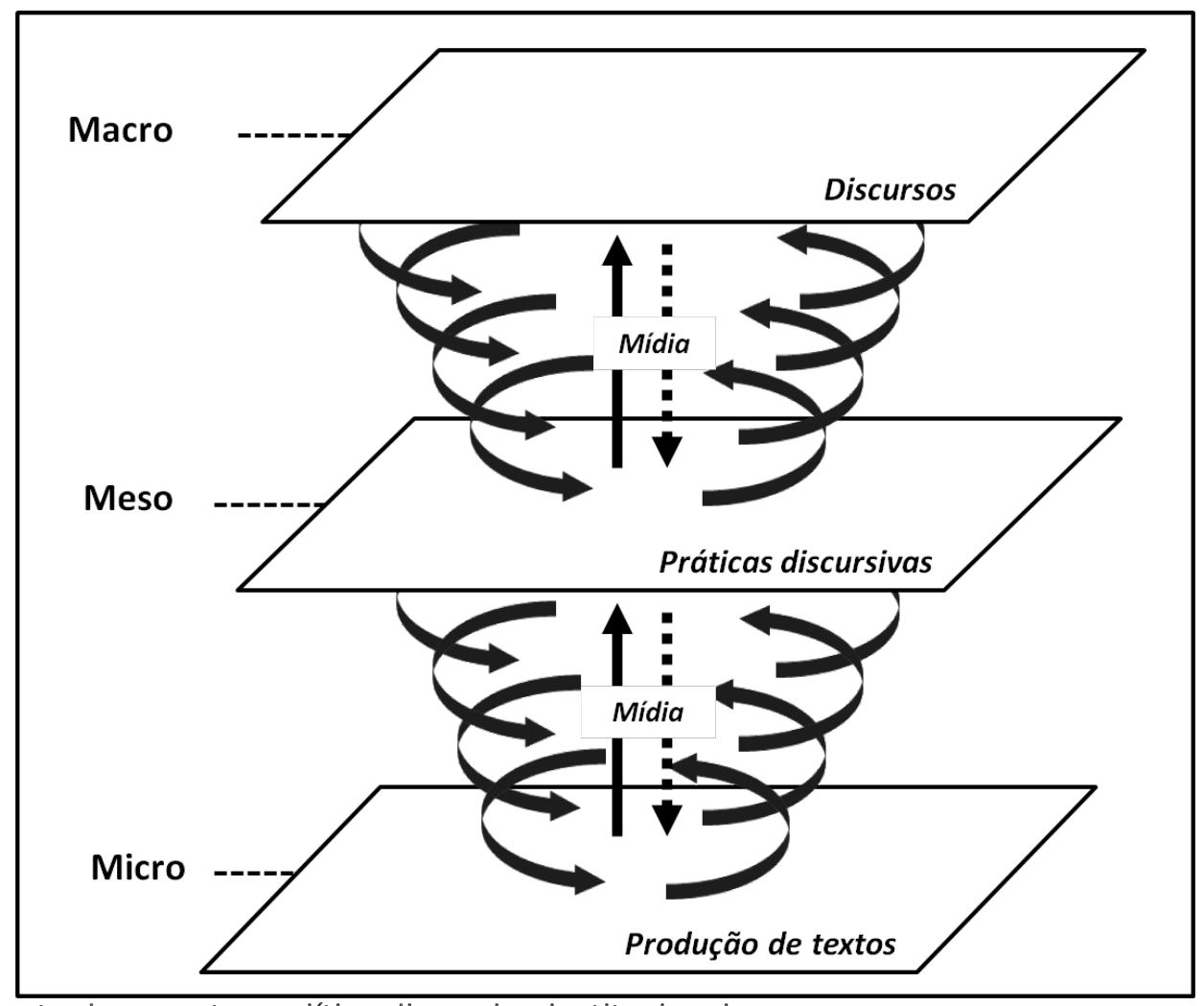

Figura 1 - Proposta de aparato analítico discursivo-institucional

Nota. Fonte: Elaborado pelos autores a partir de Phillips, Lawrence e Hardy (2004, p. 641).

A mídia, no presente ensaio teórico, é entendida como um ator relevante no processo de estruturação da realidade que, baseada em seus valores e crenças, pode contribuir tanto para a 'tradução' das características do contexto institucional quanto para a própria construção social desse mesmo contexto, sendo assumida, respectivamente, como organização e como ator relevante para o processo de institucionalização. Além disso, contribui para a transformação da organização da vida social cotidiana no tempo e no espaço, mediante criação de diferentes formas de ação e interação entre indivíduos e organizações, desenvolvendo diversos tipos de atividades nas quais se empregam vários tipos de recursos, que servem a distintas, porém sobrepostas, formas de exercício de poder (Thompson, 1995)". Nesses termos, reforça-se o significativo grau de influência na realidade social 
(nas esferas institucional, organizacional e individual) que a mídia possui por meio das ações e eventos que nelas sucedem, cotidianamente (Fairclough, 1995). Diante disto, apresenta-se, na Figura 1, um aparato analítico discursivo-institucional, inspirado no modelo apresentado por Phillips, Lawrence e Hardy (2004, p. 641), que insere a importância da mídia tanto no processo de constituição e institucionalização de um discurso (bottom-up) quanto no processo de condicionante da ação social inerente ao discurso institucionalizado (top-down).

Dentre os possíveis tipos de discursos a serem produzidos a partir do entendimento da mídia como um ator organizacional relevante em um campo, elenca-se dois: (i) o discurso midiático, que se refere aos discursos expressos nos meios de comunicação que refletem ideias, sentidos, significados e questões ideológicas da mídia, também enquanto instituição social; e (ii) os discursos organizacionais, que se referem aos discursos originados nas próprias organizações e são orientados para a difusão e legitimação de ações por meio dos textos que os embasam. Com efeito, ao afirmar a existência de uma relação entre discurso midiático e discurso organizacional, é possível estabelecer proposições de pesquisa diferentemente combináveis: (2.1.a) investigar a influência recursiva entre esses discursos; (2.1.b) investigar os mecanismos que habilitam e restringem essas influências nos contextos organizacionais; (2.1.c) investigar os efeitos desses discursos em/entre campos organizacionais; e, (2.1.d) investigar os efeitos intertextuais/interdiscursivos na legitimidade, endosso e ressonância social, bem como seu papel ativo na construção dos padrões institucionais vigentes, debruçando-se sobre processos de (des)institucionalização de práticas e modelos de gestão nas organizações.

Sendo assim, resta refletir sobre quais seriam alguns dos percursos metodológicos cabíveis, quando da aplicação desse arcabouço teórico a uma análise organizacional.

\section{Implicações e Possibilidades Metodológicas}

O modelo de análise de discurso tal como proposto e ilustrado pela Figura 2 pode ser passível de aplicação a múltiplas localidades e a diferentes objetos de estudo, principalmente para pesquisas de natureza qualitativa que sustentam foco descritivo e exploratório, preferencialmente conjugadas com um recorte temporal seccional-retrospectivo e, quando viável, também longitudinal (Vieira, 2006). Em termos de nível de análise e de procedimentos metodológicos previstos, afirma-se ser relevante atinar para questões (i) multinível, na medida em que se procura compreender aspectos em níveis grupal, organizacional e macro-institucional, e (ii) multimétodo, em razão da possibilidade de se combinar diferentes métodos qualitativos a fim de abordar e compreender melhor o fenômeno da influência discursiva da mídia em diferentes organizações e campos organizacionais (Buchanan \& Bryman, 2009).

É importante salientar que a unidade de análise deste modelo recai nas práticas discursivas das organizações. Isto se deve ao entendimento de que a linguagem em uso é fundamental para a produção dos discursos mediante seu uso na constituição das práticas sociais cotidianas de uma organização, o que enfatiza a dimensão semântico-pragmática do cotidiano (Mattos, 2006) como um fator elucidativo chave para o adequado emprego e aprimoramento do modelo de Phillips, Lawrence e Hardy (2004; 2006). Estudos de caso únicos ou múltiplos podem compor as estratégias de pesquisa (Stake, 2000), visando não apenas riqueza de evidências empíricas na singularidade de casos, mas também estabelecer comparativos e condições de paralelismo analítico em termos de natureza, dinâmica e mecanismos entre diferentes tipos de discursos, além dos impactos destes discursos nas práticas organizacionais e em campos cujas características possam auxiliar na exploração de diferenças e similaridades. Esta exploração requer cuidados nos procedimentos de coleta e análise do material empírico.

No procedimento de coleta, o material empírico pode ser originado tanto de fontes primárias quanto fontes secundárias (Silverman, 2009). As fontes primárias referem-se principalmente ao material gerado de (i) entrevistas com roteiros abertos e/ou semiestruturados realizadas com sujeitos intencionalmente selecionados pela sua relevância e experiência atreladas aos casos; e (ii) atividades de observação em distintos graus a partir de inserção negociada em organizações selecionadas como campos de estudo. Tanto a condução de entrevistas quanto as observações para a coleta dos dados primários dependem de condições de acesso e aceitação de participação das empresas selecionadas, cuja representatividade deve ser avaliada e justificada. As fontes secundárias, por sua vez, referem-se principalmente a documentos, os quais também são considerados relevantes, de modo a poder compor quadros ilustrando os contextos políticos, econômicos, sociais e históricos dos discursos e dos campos em que se pretende analisar as influências recursivas entre aqueles e as organizações. Para tanto, precisa-se reunir documentos oficiais particulares e públicos; para o primeiro tipo, consideram-se relatórios, manuais procedurais, regimentos e normativas, atas de reunião, informações veiculadas em sistemas de tecnologia da 
informação e comunicação (ex.: e-mails); para o segundo tipo, consideram-se as matérias áudiotelevisivas e impressas em jornais e revistas que se configurem como bens simbólicos comercializáveis na figura de informações em que, de forma manifesta ou latente, subjazam os discursos a serem analisados.

Uma vez considerada a mídia como um ator organizacional central, é ampla a gama de veículos de comunicação (de massa e de nicho) impressos, eletrônicos, auditivos e televisivos voltados à temática dos negócios, fascículos e cadernos econômico-empresariais de jornais, portais eletrônicos de gestão e negócios e mídias sociais em plataforma WEB 2.0 que podem ser considerados para estudo, levando em conta critérios como tiragem e circulação expressivas em cenário regional/nacional, bem como alcance, visibilidade e influência no que se convenciona chamar, contemporaneamente, de 'Mercado do Business' ou também de 'Management Industry'.

Para as fontes de dados secundários, confere-se importância central ao 'texto' - enquanto mensagem de produção midiática. Como sugere Meyrowitz (2009), a caracterização do meio midiático compreende diversos elementos, a saber: o tipo de informação sensorial (uni- ou multisensorial); a(s) forma(s) de transmissão da informação; o grau de verossimilhança entre o tipo de meio e a realidade; a natureza uni- ou multi-direcional da comunicação envolvida; a natureza sequencial ou simultânea do intercâmbio de informação; o grau e o tipo de controle dos usuários sobre a recepção e transmissão da informação; os requisitos materiais e virtuais que medeiam as atividades midiáticas; o grau e o tipo de intervenção/manipulação humana necessária ou possível para que se crie uma mensagem; o escopo e a natureza da disseminação do meio em si; a durabilidade e a portabilidade do meio midiático; a complexidade em se aprender a codificar e a decodificar mensagens em um meio; as formas físicas e virtuais pelas quais uma mídia interage com outra.

Assim, parte-se do texto enquanto insumo para se acessar e conhecer sua textualidade - ou seja, a carga de características próprias que o configura como 'texto' -, no intuito último de se alcançar a compreensão sobre o 'contexto'. Dessa forma, os sete padrões de textualidade que Bentes e Rezende (2008) elencam - coesão, coerência, intencionalidade, informatividade, aceitabilidade, situacionalidade e, intertextualidade - oferecem uma via de acesso a situação, ao cenário social, ao campo semiótico e, por fim, ao(s) campo(s) social(is) que configuram o que é o contexto em que se produzem textos e mensagens que são midiatizadas. Isso envolve informações veiculadas em sistemas de tecnologia da informação e comunicação (em WEB 2.0 e em mídias sociais, por exemplo), na forma de textos produzidos em matérias áudio-televisivas (virtuais e impressas) de jornais e revistas que se configurem como bens simbólicos comercializáveis na figura de informações em que, de forma manifesta ou latente, subjazam discursos a serem analisados (Kaplan \& Haenlein, 2010; Hodgetts \& Chamberlain, 2009).

Já no procedimento de análise desse material coletado, contempla-se a lógica multimétodo sugerida por Buchanan e Bryman (2009). Isso significa dizer que, segundo determinados recortes espaciotemporais, é possível empregar diversos procedimentos e métodos analíticos como: (i) análises de conteúdo de ordem temática (Dellagnelo \& Silva, 2005), (ii) análises da linguagem em uso mediante diferentes possibilidades combinatórias como, por exemplo, análise de frames, análises narratológicas, análise de conversação, análise da retórica, análise de 'mensagens institucionais' (Fairhurst \& Cooren, 2004; Harmon, Green Jr. \& Goodnight, 2015; Lammers \& Garcia, 2014; Mattos, 2006) e (iii) a análise interpretativa das influências multicausais dos discursos (Fairclough, 1995; Phillips \& Domenico, 2009; Phillips, Lawrence \& Hardy, 2004), no processo de delineamento, identificação e categorização de textos que possibilitem aglutinar-se enquanto componentes de discursos, podendo ser assistidos por software específico de análise qualitativa, quando nas etapas de tratamento e classificação textuais. Cruciais a todos esses procedimentos salvaguardadas a coerência nas suas escolhas e as concatenações conforme objeto e problemática sob investigação - são (i) a atenção e preocupação com a clareza das escolhas, (ii) a evidenciação procedural pautada por protocolos norteadores das etapas de tratamento e classificação, e (iii) a consciência dos trade-offs e limitações inerentes aos estudos empíricos organizacionais. Tomados tomados em conjunto, esses elementos implicam diretamente questões de validade e confiabilidade (Leicht \& Palmer, 2010)".

Considerando a contextualização, primeiramente em caráter nacional, do conjunto de organizações midiáticas que interessam considerar em pesquisas, como as sugeridas aqui, se fazem necessário:

- caracterizar a trajetória política, econômica, social e histórica referente a um contexto institucional de referência para análise de práticas ou modelos de gestão organizacional vigentes; 
- caracterizar os discursos midiáticos por meio de mecanismos (sociais, técnicos, etc.) pertinentes a sua (re)produção e que condicionam a difusão e institucionalização de práticas e modelos de gestão organizacionais;

- analisar de que maneira os discursos midiáticos influenciam práticas organizacionais como um todo, bem como questões estruturais e de modelos de gestão (sustentáveis, participativos, colaborativos, competitivos);

- analisar como os discursos midiáticos são influenciados por diferentes práticas organizacionais; e,

- analisar de que forma os discursos midiáticos influenciam a legitimidade de práticas e de modelos de gestão, por meio da (re)construção social de determinados padrões institucionais, juntamente com outras organizações de setores de atividade econômica e da sociedade civil.

A partir da consideração destas ações e coerente ao modelo de análise de discurso proposto por Phillips, Lawrence e Hardy (2004), evidenciam-se quatro etapas de pesquisa que podem ser tomadas como complementares: (i) a caracterização da trajetória política, econômica, social e histórica referente a um contexto institucional de referência, levando em conta atores e eventos relevantes; (ii) a identificação dos mecanismos sociais, técnicos e de outra natureza, empregados na (re)produção dos discursos por organizações elencadas; (iii) a análise dos processos recursivos envolvendo as influências produzidas pelos discursos em campos e em organizações, bem como das influências provenientes de campos e de organizações, nos próprios discursos; e, (iv) a análise interpretativa da participação discursiva de atores organizacionais relevantes nos processos de (re)construção social de determinados padrões institucionais vigentes. Dessa forma, analiticamente, é sensível aos mecanismos microssociais ligados a três níveis indissociáveis para o entendimento do discurso de organizações em determinados campos organizacionais - a saber: a fala; as práticas; e os significados (re)produzidos pela linguagem em uso -, bem como ao processo de (re)produção de práticas discursivas enquanto um fenômeno transversal aos níveis micro, meso e macro-societal da realidade social.

\section{Reflexões Finais}

Este ensaio proporciona nova percepção ao entendimento de problemas reais e contemporâneos a partir da consideração da mídia como um ator organizacional relevante em qualquer que seja o campo organizacional em questão (Fairclough, 1995; Thompson, 1995), principalmente quando se compreende as organizações como sistemas sociais abertos e não apenas passivos, mas, sobretudo, ativos na edificação do tecido social, impactando inevitavelmente na vida sociedade civil, bem como em diversas outras organizações, direta ou indiretamente (Scott, 2008a). Ainda que o conhecimento científico seja destinado a um público-alvo mais específico, a noção de influência multinível a qual o objeto em foco alude, repercute em termos práticos para a própria dinâmica cotidiana da vida organizacional, tendo em vista o objetivo de identificar e explicar, analiticamente, as práticas discursivas que sustentam e são sustentadas pelas organizações midiáticas, assim como as respostas da influência destas, por parte das organizações integrantes de esferas da vida institucional (Rodrigues \& Dellagnelo, 2013; Scott, 2008b; Van de Ven \& Johnson, 2006).

Não obstante, ao desvelar a influência dos discursos midiáticos sobre as questões de legitimidade, endosso e ressonância social, bem como seu papel ativo na construção dos padrões institucionais vigentes, contribui-se relevantemente para compreensão dos padrões de decisões organizacionais frente ao ambiente e campo de sua atuação, o que em última análise aprofunda o conhecimento a respeito das ações organizacionais e de seu papel na constituição do contexto contemporâneo. Desse modo, considerando a mídia um ator organizacional relevante no processo de institucionalização e também como sistema simbólico, a problemática passa então a ser a análise de como os discursos midiáticos participam da (re)construção social de padrões institucionais vigentes e influenciam a legitimidade de práticas e modelos de gestão em determinados campos organizacionais.

A primeira contribuição desse ensaio está no aprimoramento do modelo analítico de Phillips, Lawrence e Hardy (2004). Foi proposto um modelo de análise de discurso para o institucionalismo organizacional mais robusto, considerando algumas críticas apontadas por Lok e Willmott (2006) acerca da natureza relativamente vaga do referido modelo analítico, como: (i) a desatenção e o não reconhecimento da centralidade da linguagem em uso na construção social da realidade, a qual acaba por condicionar uma ideia muito mais estruturalista e menos semântico-pragmática para as questões de (re)produção dos discursos organizacionais; (ii) por conta desse equívoco em relação ao 
papel central da linguagem, uma subsequente desatenção da importância em se tomar a prática social discursiva como elemento explicativo chave, quando na investigação do empírico; (iii) e certa esterilidade das questões que tematizam relações de poder e influências ideológicas na (re)produção dos discursos organizacionais, ressoando nos padrões institucionais vigentes. Assim, a revisão analítica desse modelo que antecede a sugestão de seu emprego em investigações empíricas como as aqui pretendidas, contribui enquanto atividade para seu refinamento, melhoramento e expansão do seu potencial de utilização em outras pesquisas científicas nos EORs, ao aclarar-se algumas problemáticas acerca da forma de apropriação da ACD de Norman Fairclough por Phillips, Lawrence e Hardy (2004; 2006), e o ato de versá-la para o institucionalismo organizacional.

Um segundo apontamento contributivo é aproximar quadros teóricos dos EORs por meio da inserção da pesquisa nacional ao debate internacional. A via processual possibilitada pelo estudo das práticas sociais discursivas em ação, mediante o entendimento contextualizado da linguagem em uso nos casos a serem estudados, contribui para esse desenvolvimento teórico da análise do discurso nos EORs - nacionais e internacionais -, em sua vertente institucionalista. Evidencia-se seu potencial de emprego conjunto a desenvolvimentos recentes do Institucionalismo Organizacional que olhem pelo exercício do poder pelo discurso no trabalho institucional de (re)produção dos padrões institucionais vigentes (Lawrence, Suddaby \& Leca, 2009. Ademais, tais questões de (re)produção podem ser abordadas de forma combinada a análise de vocabulários e eventos comunicativos que subsidiam e ancoram lógicas institucionais (Ocasio, Loewenstein \& Nigam, 2015), ou ainda pelas questões de (re)produção de vocabulários e eventos comunicativos que subsidiam e ancoram lógicas institucionais (Ocasio, Loewenstein \& Nigam, 2015). Além disso, contribui ainda para outras formas de análise do discurso segundo teorias convergentes ao institucionalismo organizacional, ou que tenham inclinação epistemológica próxima ou similar, a exemplo das interpretativistas (Heracleous, 2004; Lammers \& Garcia, 2014), estruturacionistas (Heracleous \& Hendry, 2000), comunicacionais (Cornelissen et al., 2015; Lammers \& Barbour, 2006; Lammers, 2011), e abordagens que se debrucem sobre a constituição comunicativa das organizações (Brummans, Cooren, Robichaud \& Taylor, 2014; Taylor \& Robichaud, 2004), para citar algumas possibilidades.

Uma terceira contribuição remete à necessidade de se refletir acerca do objeto empírico 'mídia', problematizando-o teoricamente, levando em conta conjuntos de características próprias a ele. Não diferentemente das maneiras de se entender a mídia expressas neste ensaio, esforços científicos contemporâneos pesquisam tanto os meios empregados na (re)produção de conteúdos midiáticos (texto-discurso), quanto os seus efeitos (atitudinais, comportamentais, cognitivos, emocionais, psicológicos), alcançando, assim, análises da relação entre as tecnologias da informação e comunicação (TICs) e a sociedade, em suas mudanças sociais, histórico e culturais, num desenvolvimento teórico que se convenciona chamar de 'Teoria da Midiatização', a qual configura-se como uma abordagem mais ampla para se investigar mídia, comunicação e dimensão social, com amparo de teorias sociais de médio alcance (Hjarvard, 2012). Em tempo, os EORs já se aproximam desse arcabouço teórico, tendo em vista a centralidade da mídia - e seu papel cada vez mais presente - em processos e práticas constitutivas das organizações e em campos organizacionais (Pallas, Jonsson \& Strannegård, 2014).

Por fim, aponta-se a contribuição potencial que esse arcabouço teórico-metodológico inspirado por Phillips, Lawrence e Hardy (2004) oferece para problemas institucionais relevantes do cotidiano organizacional, ao se indicar, aqui, a análise do discurso (enquanto método) aplicada ao discurso midiático influente em campos organizacionais. Entretanto, o potencial desse modelo analítico discursivo se estende para outros domínios empíricos, podendo ser aplicado a outros objetos dos estudos organizacionais, que não estritamente as organizações midiáticas.

\section{Notas}

1. A partir tanto de Phillips, Lawrence e Hardy (2004), quanto da réplica deles à crítica de Lok e Willmott (2006) em Phillips, Lawrence e Hardy (2006), é possível depreender que, embora aqueles autores partam de uma inspiração/derivação na 'Análise Crítica do Discurso' (ACD) de Norman Fairclough, eles não trazem à reboque a epistemologia estruturalista do método deste último, mas, muito mais, utilizam-se da relação 'texto' $\leftrightarrow$ 'prática discursiva' $\leftrightarrow$ 'discurso' para argumentar que isso configura uma dinâmica categorial importante para se pesquisar discurso, à luz do institucionalismo organizacional. Nesse tocante, o que Phillips, Lawrence e Hardy (2004) operam é assumir uma análise da categoria social 'discurso' onde a questão da criticidade (ou do criticismo) se embute na análise das relações de poder subjacentes à constituição de tal categoria, não mais necessariamente tendo que assumir o rótulo "crítica" da expressão "Análise Crítica do Discurso" que o método de Norman Fairclough convencionou estabelecer. Com isso, não se trata de realizar um esvaziamento da acepção crítica do método em si, mas sim de indicar que essa Análise de Discurso, em particular, não é exatamente a mesma 'Análise Crítica do Discurso' (ACD) de Norman Fairclough, apenas 
tendo dela tomado emprestado a articulação categorial indicada. Tal prática de "tomar emprestado" categorias conceituais de outras abordagens teóricas ainda que não as vulgarizando, nem necessariamente incorrendo em contradição de ordem epistemológica, é extensivamente explicada em Whetten, Felin e King (2009). Com efeito, a intenção de Phillips, Lawrence e Hardy (2004; 2006) em desenvolverem abordagem mais ampla para uma análise de discurso nos Estudos Organizacionais se concretiza ao buscar amparo na manutenção da perspectiva construtivista, realizando subsunção parcial das contribuições da virada discursiva às estruturas axiomáticas do institucionalismo organizacional, ao mesmo tempo em que se distancia de premissas althusserianas e foucaultianas que a ACD de Norman Fairclough sustenta.

2. Este trabalho contou com recurso financeiro captado a partir do edital "Edital MCTI/CNPq/MEC/CAPES n 43/2013".

\section{Referências}

Alvesson, M., \& Kärreman, D. (2000a) Taking the linguistic turn in organizational research: challenges, responses, consequences. The Journal of Applied Behavioral Science, 36(2), 136-158.

Alvesson, M., \& Kärreman, D. (2000b) Varieties of discourse: on the study of organizations through discourse analysis. Human Relations, 53(9), 1125-1149.

Astley, W. G., \& Zammuto, R. F. (1992) Organization science, managers, and language games. Organization Science, 3(4), 443-460.

Bentes, A. C., \& Rezende, R. C. (2008). Texto: conceitos, questões e fronteiras [ con]textuais. In I. Signorini (Org.). (Re)discutir texto, gênero e discurso (pp. 19-46). São Paulo: Parábola Editorial.

Berger, P. L., \& Luckmann, T. (2003). A construção social da realidade. Petrópolis: Vozes.

Brummans, B. H. J. M., Cooren, F., Robichaud, D. \& Taylor, J. R. (2014). Approaches to the communicative constitution of organizations. In L. L. Putnam, \& D. K. Mumby (Eds.). The SAGE handbook of organizational communication: advances in theory, research, and methods (pp. 173194). London, Thousand Oaks, CA \& New Dehli: Sage Publications.

Buchanan, D. A., \& Bryman, A. (2009). The organizational research context: properties and implications. In D. A. Buchanan, \& A. Bryman (Eds.). The SAGE handbook of organizational research methods (pp. 1-18). London, Thousand Oaks, CA \& New Dehli: Sage Publications.

Cornelissen, J. P., Durand, R., Fiss, P. C., Lammers, J. C, \& Vaara, E. (2015). Putting communication front and center in institutional theory and analysis. Academy of Management Review, 40(1), 10-27.

Czarniawska, B. (2013) Things and words. Journal of Management Change, 13(3), 362-367.

Dellagnelo, E. H. L., \& Silva, R. C. (2005). Análise de conteúdo e sua aplicação em pesquisa na administração. In M. M. F. Vieira, \& D. M. Zouain (Orgs.). Pesquisa qualitativa em administração: teoria e prática (pp. 97-118). Rio de Janeiro: Editora FGV.

Dimaggio, P. J. (1988). Interest and agency in institutional theory. In L. G. Zucker (Ed). Institutional patterns and organizations: culture and environment (pp. 3-21). Cambridge: Ballinger.

Fairclough, N. (1995). Media discourse. London: Hodder Arnold Publication.

Fairclough, N. (2001). Discurso e mudança social. Brasília: Editora Universidade de Brasília.

Fairclough, N. (2005) Discourse analysis in organization studies: the case for critical realism. Organization Studies, 26(6), 915-939.

Fairhurst, G. T., \& Cooren, F. (2004). Organizational language in use: interaction analysis, conversation analysis and speech act semantics. In D. Grant, C. Hardy, C. Oswick, \& L. Putnam (Eds.). The SAGE handbook of organizational discourse (pp. 131-152). London: Sage Publications

Farjoun, M. (2010) Beyond dualism: stability and change as a duality. Academy of Management Review, 35(2), 202-225.

Friedland, R., \& Alford, R. R. (1991). Bringing society back in: symbols, practices, and institutional contradictions. In W. W. Powell, \& P. J. Dimaggio (Eds.). The new institutionalism in organizational analysis (pp. 232-263). Chicago: The University of Chicago Press.

Grant, D., Hardy, C., Oswick, C. \& Putnam, L. (2004). Introduction: organizational discourse: exploring the field. In D. Grant, C. Hardy, C. Oswick, \& L. Putnam (Eds.). The SAGE handbook of organizational discourse (pp. 1-36). London: Sage Publications. 
Grant, D., Keenoy, T. \& Oswick, C. (1998). Introduction - organizational discourse: of diversity, dichotomy and multi-disciplinarity. In D. Grant, T. Keenoy, \& C. Oswick (Eds.). Discourse and organization (pp. 1-13). London: Sage Publications.

Greenwood, R., Oliver, C., Sahlin, K. \& Suddaby, R. (2008). Introduction. In R. Greenwood, C. Oliver, K. Sahlin, \& R. Suddaby (Eds.). The SAGE handbook of organizational institutionalism (pp. 1-46). London, Thousand Oaks, CA \& New Dehli: Sage Publications.

Heracleous, L. (2004). Interpretivist approaches to organizational discourse. In D. Grant, C. Hardy, C. Oswick, \& L. Putnam (Eds.). The SAGE handbook of organizational discourse (pp. 175-192). London: Sage Publications.

Hardy, C., Palmer, I. \& Phillips, N. (2000) Discourse as a strategic resource. Human Relations, 53(9), 1227-1248.

Harmon, D. J., Green Jr., S. E., \& Goodnight, G. T. (2015). A model of rhetorical legitimation: the structure of communication and cognition underlying institutional maintenance and change. Academy of Management Review, 40(1), 76-95.

Heracleous, L., \& Hendry, J. (2000) Discourse and the study of organization: toward a structurational perspective. Human Relations, 53(10), 1251-1286.

Hjarvard, S. (2012) Midiatização: teorizando a mídia como agente de mudança social e cultural. MATRIZes, 5(2), 53-91.

Hodgetts, D., \& Chamberlain, K. (2009). Analysing news media. In U. Flick (Ed.). The SAGE handbook of qualitative data analysis (pp. 380-393). London, Thousand Oaks, CA \& New Dehli: Sage Publications.

Kaplan, A. M., \& Haenlein, M. (2010) Users of the world, unite! The challenges and opportunities of Social Media. Business Horizons, 53(1), 59-68.

Lammers, J. C. (2011) How institutions communicate: institutional messages, institutional logics, and organizational communication. Management Communication Quarterly, 25(1), 154-182.

Lammers, J. C., \& Barbour, J. B. (2006) An institutional theory of organizational communication. Communication Theory, 16(3), 356-377.

Lammers, J. C., \& Garcia, M. A. (2014). Institutional theory. In L. L. Putnam, \& D. K. Mumby (Eds.). The SAGE handbook of organizational communication: advances in theory, research, and methods (pp. 195-216). 3. ed. London, Thousand Oaks, CA \& New Dehli: Sage Publications.

Lawrence, T. B. (2008). Power, institutions and organizations. In R. Greenwood, C. Oliver, K. Sahlin, \& R. Suddaby (Eds.). The SAGE handbook of organizational institutionalism (pp. 170-197). London, Thousand Oaks, CA \& New Dehli: Sage Publications.

Lawrence, T. B.; Suddaby, R.; \& Leca, B. (2009). Introduction: theorizing and studying institutional work. In T. B. Lawrence, R. Suddaby, \& B. Leca (Eds.). Institutional Work: actors and agency in institutional studies of organizations (pp. 1-27). Cambridge: Cambridge University Press.

Leicht, S., \& Palmer, I. (2010) Analyzing texts in context: current practices and new protocols for critical discourse analysis in organization studies. Journal of Management Studies, 47(6), 1194-1212.

Lok, J., \& Willmott, H. (2006) Dialogue - Institutional theory, language and discourse analysis: a comment on Phillips, Lawrence and Hardy. Academy of Management Review, 31(2), 477-480.

Lounsbury, M. (2003). The problem of order revisited: towards a more critical institutional perspective. In R. Westwood, \& S. R. Clegg (Eds.). Debating organization: point-counterpoint in organization studies (pp. 210-219). Malden: Blackwell Publishing.

Machado-Da-Silva, C. L., Fonseca, V. S. da, \& Crubellate, J. M. (2005) Estrutura, agência e interpretação: elementos para uma abordagem recursiva do processo de institucionalização. Revista de Administração Contemporânea, Curitiba, 9(1a. ed. Especial), 9-39.

Mattos, P. L. C. L. (2006) Análise de entrevistas não estruturadas: da formalização à pragmática da linguagem. In C. K. Godoi, R. Bandeira-De-Mello, \& A. B. Silva (Orgs.). Pesquisa qualitativa em estudos organizacionais: paradigmas, estratégias e modelos (pp. 347-373). São Paulo: Saraiva.

Meyrowitz, J. (2009). Medium theory: an alternative to the dominant paradigm of media effects. In R. L. Nabi, \& M. B. Oliver (Eds.), The SAGE handbook of media processes and effects (pp. 517-530). 1st ed. London, Thousand Oaks, CA \& New Dehli: Sage Publications. 
Ocasio, W., Loewenstein, J., \& Nigam, A. (2015). How streams of communication reproduce and change institutional logics: the role of categories. Academy of Management Review, 40(1), 28-48.

Oliveira, M. A. (2006). Reviravolta lingüístico-pragmática na filosofia contemporânea. São Paulo: Edições Loyola.

Oliver, C. (1991) Strategic responses to institutional processes. Academy of Management Review, 16(1), 145-179.

Oliver, C. (1992) The antecedents of deinstitutionalition. Organization Studies, 13(4), 563-588.

Pallas, J., Strannegård, L., \& Jonsson, S. (Eds.). (2014). Organizations and the media: organizing in a mediatized world. New York: Routledge.

Phillips, N., \& Domenico, M. D. (2009). Discourse analysis in organizational research: methods and debates. In D. A. Buchanan, \& A. Bryman (Eds.). The SAGE handbook of organizational research methods (pp. 549-565). 1. ed. London, Thousand Oaks, CA \& New Dehli: Sage Publications.

Phillips, N., Lawrence, T. B., \& Hardy, C. (2004) Discourse and institutions. Academy Management Review, 29(4), 635-652.

Phillips, N., Lawrence, T. B., \& Hardy, C. (2006) Dialogue - Discussing "Discourse and institutions": a reply to Lok and Willmott. Academy Management Review, 31(2), 480-483.

Phillips, N., \& Malhotra, N. (2008). Taking social construction seriously: extending the discursive approach in institutional theory. In R. Greenwood, C. Oliver, K. Sahlin, \& R. Suddaby (Eds.). The SAGE handbook of organizational institutionalism (pp. 702-720). London, Thousand Oaks, CA \& New Dehli: Sage Publications.

Phillips, N., \& Oswick, C. (2012) Organizational discourse: domains, debates, and directions. The Academy of Management Annals, 6(1), 435-481.

Rice, R. E., \& Leonardi, P. M. (2014). Information and communication technologies in organizations. In L. L. Putnam, \& D. K. Mumby (Eds.). The SAGE handbook of organizational communication: advances in theory, research, and methods (pp. 425-448). 3. ed. London, Thousand Oaks, CA \& New Dehli: Sage Publications.

Rodrigues, M. S., \& Dellagnelo, E. H. L. (2013) Do discurso e de sua análise: reflexões sobre limites possibilidades na ciência da Administração. Cadernos EBAPE.BR, 11(4), 621-635.

Rorty, R. (1994). A filosofia e o espelho da natureza. Rio de Janeiro: Relume-Dumará.

Schmidt, V. A. (2008) Discursive institutionalism: the explanatory power of ideas and discourse. Annual Review of Political Science, 11, 303-326.

Scott, W. R. (2008a). Institutions and organizations: ideas and interests. Thousand Oaks: Sage.

Scott, W. R. (2008b) Lords of the dance: professionals as institutional agents. Organization Studies, 29(2), 219-238.

Silverman, D. (2009). Interpretação de dados qualitativos: métodos para análise de entrevistas, textos e interações. Porto Alegre: Artmed.

Stake, R. E. (2000). Case studies. In N. K. Denzin, \& Y. S. Lincoln (Eds.). The SAGE handbook of qualitative research (pp. 435-454). London: Sage Publications.

Stern, D. G. (2003). The practical turn. In S. P. Turner, \& P. A. Roth (Eds.). The blackwell guide to the philosophy of the social sciences (pp. 185-206). Malden: Blackwell Publishing.

Suchman, M. C. (1995) Managing legitimacy: strategic and institutional approaches. Academy of Management Review, 20(3), 571-610.

Taylor, J. R., \& Robichaud, D. (2004) Finding the organization in the communication: discourse as action and sensemaking. Organization, 11(3), 395-413.

Thompson, J. B. (1995). A mídia e a modernidade: uma teoria social da mídia. Petrópolis: Vozes.

Van de Ven, A. H., \& Johnson, P. E. (2006) Knowledge for theory and practice. Academy of Management Review, 31(4), 802-821.

Vieira, M. M. F. (2006). Por uma boa pesquisa (qualitativa) em administração. In M. M. F. Vieira, \& D. M. Zouain (Orgs.). Pesquisa qualitativa em administração: teoria e prática (pp. 13-28). 2nd. ed. Rio de Janeiro: Editora FGV. 
Westwood, R., \& Clegg, S. R. (2003). Power and institutions - commentary: the dynamics of institutions. In R. Westwood, \& S. R. Clegg (Eds.) Debating organization: point-counterpoint in organization studies (pp. 208-210). Malden: Blackwell Publishing.

Whetten, D. A., Felin, T., \& King, B. G. (2009). The practice of theory borrowing in organizational studies: current issues and future decisions. Journal of Management, 35(3), p. 537-563.

Wooten, M.; \& Hoffman, A. J. (2008). Organizational fields: past, present and future. In R. Greenwood, C. Oliver, K. Sahlin, \& R. Suddaby, R. (Eds.). The SAGE handbook of organizational institutionalism (pp.702-720). London, Thousand Oaks, CA \& New Dehli: Sage Publications

Zoller, H. M. (2014). Power and resistance in organizational communication. In L. L. Putnam, \& D. K. Mumby (Eds.). The SAGE handbook of organizational communication: advances in theory, research, and methods (pp. 595-618). (3 ed.). London, Thousand Oaks, CA \& New Delhi: Sage Publications. 